\title{
Hubungan antara Kategori Kardiotokografi dan Jenis Persalinan dan Asfiksia Neonatus
}

\author{
Nurul Husna, ${ }^{1}$ Vita Murniati Tarawan, ${ }^{1}$ Dwi Prasetyo ${ }^{2}$ \\ ${ }^{1}$ Fakultas Kedokteran Universitas Padjadjaran, Bandung, Jawa Barat, Indonesia \\ ${ }^{2}$ Departemen Ilmu Kesehatan Anak, Fakultas Kedokteran, Universitas Padjadjaran/ \\ RSUP Dr. Hasan Sadikin Bandung, Jawa Barat, Indonesia \\ Korespondensi: husnanuru1271187@gmail.com
}

\begin{abstract}
Abstrak
Tujuan: Melihat hubungan antara pola kardiotokografi dan hasil luaran (cara persalinan dan status asfiksia neonatus).

Metode: Penelitian ini observasional analitik retrospektif dengan desain case-control. Penelitian melibatkan pasienpasien yang melahirkan di RS Hasan Sadikin Bandung antara 2019-2020. Kriteria inklusi adalah pasien dengan kehamilan normal dan/atau dengan kehamilan patologis, pasien dengan usia gestasi 37-40 minggu, kehamilan dengan janin tunggal dan pasien dengan induksi persalinan. Kriteria eksklusi mencakup data pemeriksaan tidak lengkap anamnesa, pemeriksaan fisik terkait kehamilan dan persalinan, rekaman kardiotokografi, dan skor APGAR menit ke-5; hambatan pertumbuhan janin intrauterine (IUGR); kelainan kongenital (cacat bawaan) dan infeksi/demam pada ibu. Penelitian ini menggunakan data sekunder dari rekam medis. Metode perekrutan sampel menggunakan consecutive admission sampling. Analisis data secara deskriptif dan analitik dilakukan.

Hasil: Rerata usia pasien adalah 26,83 \pm 7 tahun. Pasien paling banyak memiliki latar belakang pendidikan tamat SMA (51,7\%). 48,3\% pasien belum pernah bersalin. 53,3\% pasien sedang hamil 39-40 minggu saat bergabung dengan penelitian ini. Rata-rata berat bayi lahir sebesar 2923,33 $\pm 385,229$ gr. Untuk APGAR Score 5' memiliki rata-rata sebesar 7,68 $\pm 2,347$. Ditemukan bahwa kategori kardiotokografi patologis secara signifikan meningkatkan terjadinya asfiksia $(\mathrm{p}=0,024)$. Kemudian, temuan kardiotokografi patologis juga secara signifikan meningkatkan pemilihan seksio sesarea sebagai metode persalinan $(\mathrm{p}<0,001)$.

Kesimpulan: Pola kardiotokografi patologis secara signifikan meningkatkan risiko munculnya asfiksia pada neonatus.
\end{abstract}

Kata kunci: Kardiotokografi, Asfiksia, Persalinan, APGAR

\section{Association between Cardiotocographic traces, and mode of delivery and asphyxia}

\begin{abstract}
Objective: the aim of this study is to evaluate the association between cardiotocographic traces and maternal and neonatal outcomes (mode of delivery and neonatal asphyxia status).

Method: This is a retrospective observational analytical case-control study involving patients delivering at Hasan Sadikin General Hospital between 2019-2020. The inclusion criteria were patients with normal pregnancies and/ or pathologic pregnancies at 37-40 weeks of gestation, singleton pregnancies and patients with induced labor. The exclusion criteria were the following: incomplete case notes (patient history, physical examination, CTG record and 5-minute APGAR score), intrauterine growth restriction (IUGR); fetal with congenital anomalies dan maternal infection and/or fever. This study utilized secondary data from patient case notes. This study employed consecutive admission sampling. Descriptive and analytical statistics were performed.

Results: Mean patient age was 26,83 \pm 7 years. 51,7\% patients were high-school graduates. 48,3\% were nulliparous. 53,3\% were at 39-40 weeks of gestation. Mean neonatal birth weight was 2923,33 $\pm 385 \mathrm{gr}$. Mean 5-minute APGAR score was 7,68 \pm 2. Pathologic CTG traces significantly increased perinatal asphyxia $(p=0,024)$. Pathologic CTG traces also significantly increased the use of caesarean section as method of delivery $(p<0,001)$.

Conclusion: Pathologic CTG traces significantly increased the likelihood of neonatal asphyxia.
\end{abstract}

Key words: Cardiotocography, Asphyxia, Delivery, APGAR 


\section{Pendahuluan}

Janin pada persalinan normal mempunyai cadangan oksigen yang adekuat dan dapat mengatasi masalah akibat kekurangan oksigen tersebut untuk sementara waktu sepanjang uterus mengalami relaksasi di antara kontraksi. ${ }^{1}$ Pada kondisi tertentu janin akan mengalami masalah dalam proses persalinan dan dapat diketahui pada saat bayi dilahirkan. ${ }^{2}$ Asfiksia perinatal merupakan ketidakmampuan bayi baru lahir untuk memulai dan mempertahankan respirasi yang cukup setelah melahirkan dan ditandai oleh penurunan pertukaran gas. ${ }^{3,4}$ Kardiotokografi telah dipakai diluas untuk mendeteksi janin dalam hubungannya dengan hipoksia. Kardiotokografi normal tidak selalu menyingkirkan asidemia janin. ${ }^{5}$ Kardiotokografi patologis memiliki kemungkinan adanya asfiksia perinatal. ${ }^{6,7}$

Apgar skor telah dipakai luas untuk mendiagnosa adanya asfiksia bayi baru lahir, meskipun tidak disarankan untuk mendiagnosa asfiksia tanpa tambahan pemeriksaan lainnya. ${ }^{8}$ Apgar skor yang rendah pada 5 menit setelah kelahiran berhubungan dengan mortalitas neonatal. ${ }^{8}$ Beberapa penelitian sebelumnya melaporkan bahwa jenis persalinan mempengaruhi luaran bayi, bayi yang dilahirkan melalui seksio sesarea cenderung membutuhkan bantuan pernapasan yang lebih besar (ventilasi mekanik dan terapi oksigen) dibandingkan bayi yang dilahirkan pervaginam. Oleh karena itu, penelitian ini diharapkan dapat memberi informasi saling keterkaitan sejumlah faktor tersebut.

\section{Metode}

Desain penelitian menggunakan desain observasional analitik retrospektif dengan rancangan penelitian case control study. Seluruh sampel yang telah memenuhi kriteria inklusi (pasien dengan kehamilan normal dan/atau dengan kehamilan patologis, pasien dengan usia gestasi 37-40 minggu, kehamilan dengan janin tunggal, pasien dengan induksi persalinan) dimasukkan sebagai subjek penelitian dan sampel yang masuk dalam kriteria eksklusi (data pemeriksaan tidak lengkap meliputi data anamnesa, data pemeriksaan fisik terkait kehamilan dan persalinan, hasil rekaman pemeriksaan kardiotokografi, dan catatan apgar score menit ke-5, hambatan pertumbuhan janin intrauterine (IUGR), bayi dengan kelainan kongenital (cacat bawaan) dan terdapat infeksi/demam pada ibu) tidak dimasukkan sebagai subjek penelitian. Subjek penelitian adalah pasien yang sudah melahirkan di Rumah Sakit Hasan Sadikin Bandung pada periode 2019-2020 dengan usia kehamilan 37-40 minggu yang sebelumnya dilakukan pemeriksaan kardiotokografi intra partum dan dilakukan pencatatan luaran bayi yang dilahirkan. Subjek penelitian terdiri dari pasien yang melahirkan serta bayi yang dilahirkan pada persalinan tersebut. Subjek penelitian di ambil secara consecutive admission sampling.

Data yang digunakan adalah data sekunder yang diperoleh dari rekam medik setelah mendapat persetujuan dari Rumah Sakit Hasan Sadikin Bandung. Semua prosedur penatalaksanaan yang didapat pasien adalah sesuai protap tatalaksana pasien di Rumah Sakit Hasan Sadikin. Penelitian ini bersifat observasional, tidak ada prosedur medis yang diterima subjek. Penelitian dilaksanakan setelah mendapat rekomendasi etik penelitian, dengan tetap memegang prinsip kerahasiaan, menghormati individu lainnya, bermanfaat dan tidak merugikan.

Analisis data dilakukan secara univariat danbivariat.Analisis univariatyang digunakan adalah analisis deskriptif yang bertujuan untuk mendeskripsikan karakteristik dan status klinis pasien serta mendeskripsikan variabel-variabel penelitian. Setiap kategori pada masing-masing karakteristik dan status klinis pasien serta variabel penelitian yang 
berskala kategorik nominal dihitung frekuensi dan proporsi serta dianalisis distribusinya. Sedangkan untuk variabel yang berskala rasio, analisis desktiptif menggunakan rentang (minimal - maksimal), median, rata-rata (mean), dan standard deviasi (SD). Analisis yang dilakukan selanjutnya bertujuan untuk mendeskripsikan variabel-variabel dependen dan independen sehingga dapat membantu analisis selanjutnya secara lebih mendalam. Selain itu, analisis secara deskriptif ini juga digunakan untuk mengetahui karakteristik subjek penelitian yang menjadi sampel penelitian.

Analisis data untuk melihat gambaran proporsi masing- masing variabel yang akan disajikan secara deskriptif dapat diuraikan menjadi analisis deskriptif dan uji hipotesis. Data yang berskala numerik seperti umur pasien dipresentasikan dengan rerata, standard deviasi, median dan range. Kemudian untuk data karakteristik sampel berupa data kategorik seperti jenis kelamin pasien maka diberikan koding dan dipresentasikan sebagai distribusi frekuensi dan persentase.

Analisis yang dilakukan harus sesuai dengan jenis masalah penelitian dan data yang digunakan. Kemudian untuk data numerik, sebelum dilakukan uji statistika data numerik tersebut dinilai dengan uji normalitas dengan menggunakan Shapiro-Wilk test. Selanjutnya analisis statistik sesuai tujuan penelitian dan hipotesis. Uji kemaknaan untuk membandingkan karakteristik dua kelompok penelitian digunakan uji t tidak berpasangan jika data berdistribusi normal dan uji Mann Whitney sebagai alternatifnya jika data tidak berdistribusi normal. Sedangkan analisis statistik untuk data kategorik diuji dengan uji chi-square apabila syarat Chi-Square terpenuhi apabila tidak terpenuhi maka digunakan uji Exact Fisher untuk tabel 2 x 2 dan Kolmogorov Smirnov untuk tabel selain 2 $\mathrm{x}$ 2. Syarat Chi Square adalah tidak ada nilai expected value yang kurang dari 5 sebanyak $20 \%$ dari tabel. Kemudian karena merupakan penelitian case control maka yang akan muncul nilai OR atau Odds Rasio yaitu dalam mengukur kekuatan hubungan sebab akibat.

Adapun kriteria kemaknaan yang digunakan adalah nilai $p$, apabila $\mathrm{p} \leq 0,05$ signifikan atau bermakna secara statistika, dan $\mathrm{p}>0,05$ tidak signifikan atau tidak bermakna secara statistik. Data yang diperoleh dicatat dalam formulir khusus kemudian diolah melalui program SPSS versi 24.0 for Windows.

\section{Hasil}

Tabel 1 Gambaran Karakteristik Pasien

\begin{tabular}{lc}
\hline \multicolumn{1}{c}{ Variabel } & $\mathbf{N}=\mathbf{6 0}$ \\
\hline Usia & \\
Mean \pm Std & $26,83 \pm 7$ \\
Median & 27,00 \\
Range (min-max) & $14,00-41,00$ \\
Pendidikan & \\
SD & $6(10,0 \%)$ \\
SMP & $14(23,3 \%)$ \\
SMA & $31(51,7 \%)$ \\
Perguruan Tinggi & $9(15,0 \%)$ \\
Paritas & \\
Nullipara & $29(48,3 \%)$ \\
Primipara & $17(28,3 \%)$ \\
Para 2 & $6(10,0 \%)$ \\
>= Para 3 & $8(13,3 \%)$ \\
Usia Gestasional & \\
$37-38$ minggu & $10(16,7 \%)$ \\
38-39 minggu & $18(30,0 \%)$ \\
39-40 minggu & $32(53,3 \%)$ \\
Berat bayi lahir & \\
Mean \pm Std & $2823,33 \pm 385$ \\
Median & $2300,00-3900,00$ \\
Range (min-max) & \\
APGAR Score 5, & \\
Mean \pm Std & \\
Median & \\
Range (min-max) & \\
\hline
\end{tabular}


Tabel 2 Perbandingan atau Hubungan Kategori Kardiotokografi dengan Asfiksia.

\begin{tabular}{lccc}
\hline \multirow{1}{*}{ Variabel } & \multicolumn{2}{c}{ Afsiksia } & \multirow{2}{*}{ Nilai P } \\
\cline { 2 - 3 } & $\begin{array}{c}\text { Ya } \\
\mathbf{N = 6}\end{array}$ & $\begin{array}{c}\text { Tidak } \\
\mathbf{N = 5 4}\end{array}$ & \\
\hline Kategori & & & $\mathbf{0 . 0 2 4 * *}$ \\
Kardiotokografi & & & \\
Patologis & $6(20,0 \%)$ & $24(80,0 \%)$ & \\
Non Patologis & $0(0,0 \%)$ & $30(100,0 \%)$ & \\
\hline
\end{tabular}

Tabel 3 Perbandingan atau Hubungan Kategori Kardiotokografi dengan Jenis Persalinan dan Asfiksia.

\begin{tabular}{|c|c|c|c|c|c|c|c|c|}
\hline \multirow[b]{3}{*}{ Variabel } & \multicolumn{4}{|c|}{ Jenis Persalinan } & \multirow[b]{3}{*}{ Nilai $\mathbf{P}$} & & & \multirow[b]{3}{*}{ Nilai $\mathbf{P}$} \\
\hline & \multicolumn{3}{|c|}{ Pervaginam } & \multirow{2}{*}{$\begin{array}{c}\begin{array}{c}\text { Per } \\
\text { abdominam }\end{array} \\
\text { Seksio } \\
\text { caesaria } \\
\mathrm{N}=\mathbf{3 4}\end{array}$} & & \multicolumn{2}{|c|}{ Asfiksia } & \\
\hline & $\begin{array}{c}\text { Normal } \\
\mathrm{N}=\mathbf{1 8}\end{array}$ & $\begin{array}{c}\text { Vakum } \\
\text { ekstraksi } \\
\mathbf{N}=1\end{array}$ & $\begin{array}{c}\text { Forcep } \\
\text { ekstraksi } \\
\mathrm{N}=7\end{array}$ & & & $\begin{array}{c}Y a \\
N=6\end{array}$ & $\begin{array}{l}\text { Tidak } \\
\mathrm{N}=54\end{array}$ & \\
\hline Kategori & & & & & $<0,001 *$ & & & 0,024 \\
\hline Kardiotokografi & & & & & * & & & $* *$ \\
\hline Patologis & $0(0 \%)$ & $0(0 \%)$ & $0(0 \%)$ & $30(100 \%)$ & & $6(20 \%)$ & $24(80 \%)$ & \\
\hline Non Patologis & $18(60 \%)$ & $1(3,3 \%)$ & $7(23,3 \%)$ & $4(13,3 \%)$ & & $0(0 \%)$ & $30(100 \%)$ & \\
\hline
\end{tabular}

Tabel 1 menjelaskan gambaran karakteristik subjek keseluruhan pasien. Untuk usia pasien memiliki rata-rata sebesar $26,83 \pm 7$ tahun. Pasien paling banyak memiliki latar belakang pendidikan tamat SMA (51,7\%). 48,3\% pasien belum pernah bersalin sebelumnya. 53,3\% pasien sedang hamil 39-40 minggu saat bergabung dengan penelitian ini. Untuk rata-rata berat bayi lahir sebesar 2923,33 \pm 385 gr. Untuk APGAR Score 5 ' memiliki rata-rata sebesar 7,68 2 .

Tabel 2 menjelaskan hubungan yang signifikan antara kategori kardiotokografi dengan asfiksia. Analisis menggunakan uji statistika Exact Fisher dengan hasil p=0,024.

Tabel 3 menjelaskan perbandingan atau hubungan kategori kardiotokografi dengan jenis persalinan dan asfiksia. Untuk analisis pada data kategorik yaitu jenis persalinan pada tabel diatas diuji dengan menggunakan uji statistika Kolmogorov smirnov. Hasil uji statistik menunjukkan bahwa keberadaan kardiotokografi patologis secara signifikan meningkatkan pemilihan seksio sesarea sebagai metode persalinan $(\mathrm{p}<0,001)$.

\section{Pembahasan}

Untuk mencapai kondisi sehat, salah satu hal yang perlu diperhatikan adalah usia saat melahirkan. Seorang wanita atau ibu yang melahirkan pada umur muda, cenderung mempunyai risiko kesehatan. Berdasarkan tabel 1 karakteristik usia pada kelompok studi memiliki nilai median 27,00. Nilai ini sedikit lebih tinggi dari hasil survey demografi kesehatan Indonesia (SDKI) tahun 2017 yaitu 22,4. Meskipun demikian usia rerata kelompok studi (26.83 \pm 7.006 tahun) masih dalam kurun reproduksi sehat yaitu $20-35$ tahun.

Tingkat pendidikan mayoritas pada kelompok studi adalah SMA, hal ini sejalan 
dengan sejumlah studi diantaranya SDKI tahun 2012, yang menyebutkan mayoritas wanita melahirkan dan mencari pertolongan persalinan memiliki tingkat pendidikan dominan yaitu tamatan Sekolah Menengah Atas.

Pada penelitian ini, kami memasukkan kriteria usia gestasi 37 - 40 minggu dengan pertimbangan kematangan paru sudah tercapai sehingga kemungkinan gangguan pernafasan yang terkait dengan prematuritas dapat disingkirkan. Luaran persalinan dari rentang usia gestasi tersebut (tabel 2) didapatkan berat rerata bayi lahir sebesar $2923.33 \pm 385.229$ gram. Berat tersebut sesuai dengan berat bayi usia cukup bulan yaitu diatas 2500 gram.

Hasil utama dari penelitian ini menunjukkan bahwa jumlah neonatus asfiksia secara signifikan lebih banyak pada kasuskasus dengan gambaran kardiotokografi yang patologis $(\mathrm{p}=0.024)$. Hasil penelitian ini sejalan dengan penelitian yang dilakukan oleh Murphy et al pada tahun 1990 dimana didapatkan hasil CTG yang abnormal terjadi pada $87 \%$ bayi dengan asfiksia $(p<0,001) .{ }^{9}$ Akan tetapi, terdapat perbedaan mendasar penelitian Murphy et al dengan penelitian ini: kriteria penegakan diagnosis asfiksia pada neonatus. ${ }^{9}$ Penelitian ini hanya menggunakan cut-off nilai 3 pada skor APGAR di menit ke-5 sedangkan penelitian Murphy et al melibatkan kriteria lain seperti $\mathrm{pH}$ arteri umbilikalis $<7$ serta skor APGAR $<7$ pada menit pertama. ${ }^{9}$

Bognadovic et al juga mendapatkan hasil yang serupa di mana didapatkan korelasi antara CTG yang abnormal dengan bayi asfiksia. ${ }^{10}$ Dalam penelitian terhadap 68 sampel dengan 40 kelompok kontrol, didapatkan hasil kardiotokografi patologis pada 45 sampel $(66,17 \%)$ dan terdapat $17,46 \%$ bayi asfiksia dengan APGAR score kurang dari 7 pada penilaian menit kelima. ${ }^{10}$ Hasil penelitian ini sesuai dengan hasil penelitian yang dilakukan oleh Bogdanovic et al. yang menyatakan hubungan signifikan antara kategori kardiotokografi dengan jenis persalinan. ${ }^{10}$

Penelitian ini juga menunjukkan bahwa pada hasil kardiotokografi yang patologis maka akan dilakukan persalinan melalui seksio sesarea. $(p<0.001)$. Hasil penelitian ini sejalan dengan penelitian yang telah dilakukan oleh Joshi et al pada tahun 2019 dimana hasil CTG menentukan metode persalinan yang akan dilakukan. ${ }^{11}$

Tabel 4 dapat dijelaskan hubungan antara kategori kardiotokografi dengan asfiksia. Dalam hal ini yang dimaksud asfiksia berat sesuai definisi operasional yaitu didapatkan Apgar score pada menit kelima $\leq 3$. Pada kelompok kategori kardiotokografi I-II (non patologis), tidak dijumpai bayi yang lahir dengan asfiksia. Sedangkan pada kelompok kategori kardiotokografi III (patologis) dari 30 bayi yang dilahirkan dengan cara seksio caesaria atas indikasi gawat janin hanya $20 \%$ yang mengalami asfiksia berat pada penilaian apgar score menit ke lima. Hal ini dapat dijelaskan bahwa usaha resusitasi perioperatif yang dilakukan terhadap ibu dan janin membuat daya kompensasi oksigenasi bayi mampu bertahan sampai dilahirkan dalam waktu yang tidak terlalu lama $(1 / 2-$ 1 jam). Selain persalinan cepat juga tindakan resusitasi bayi baru lahir oleh tim pediatrik sangat membantu bayi yang berada dalam periode kritis pada masa transisi untuk mempertahankan fungsi sirkulasi dan respirasi sehingga bayi tidak jatuh dalam kondisi asfiksia berat. Hal ini tidak terlepas dari deteksi dini kegawatan janin dengan menggunakan kardiotokografi sebagai alat pemantauan janin intrauterine. Hal ini juga menunjukkan adanya hubungan antara kategori kardiotokografi dengan luaran bayi yaitu asfiksia.

Kelebihan pertama penelitian ini adalah penelitian ini memberikan konfirmasi bahwa CTG memang dapat dipakai untuk menentukan potensi keluaran neonatus serta 
potensi keluaran asfiksia pada neonatus. Kelebihan kedua berasal dari profil fasilitas kesehatan kami karena penelitian ini dilaksanakan di fasilitas kesehatan tersier dan rujukan Jawa Barat sehingga memiliki fasilitas kesehatan yang lengkap. Terakhir, penelitian dengan tema ini tidak banyak dilakukan di Indonesia dan memperkaya repositori pada bidang ini.

Akan tetapi, penelitian ini masih memiliki berbagai kekurangan. Kekurangan pertama melibatkan jumlah sampel pada penelitian ini. Meskipun jumlah sample penelitian ini memenuhi rumus perhitungan sampel yang valid, akan lebih baik bila jumlah subjek pada penelitian ini lebih besar. Sebaiknya dilakukan sebuah penelitian yang menggunakan total sampling untuk pasienpasien yang melahirkan di fasilitas kesehatan ini untuk mendapatkan gambaran yang lebih akurat dengan power yang lebih tinggi.

Kelemahan kedua berkaitan dengan penegakan diagnosis asfiksia yang dipakai pada penelitian ini. Kriteria asfiksia pada penelitian ini ditegakkan hanya dari skor APGAR. Meskipun menurut ACOG skor APGARmerupakansuatuasesmenyangpaling mudah untuk menilai derajat kesejahteraan neonatus, skor APGAR sebaiknya disuplementasi dengan pemeriksaan lain untuk mendeteksi terjadinya asfiksia dan derajatnya. ${ }^{55}$ Salah satu penelitian awal mengenai kardiotokografi intrapartum dan kesejahteraan janin menggunakan berbagai kriteria untuk mendefinisikan asfiksia berat, contohnya $\mathrm{pH}$ arteri umbilikalis $<7$; ventilasi tekanan positif intermiten, serta tandatanda ensefalopati (contoh: kejang). Akan lebih baik bila pada penelitian berikutnya metode deteksi asfiksia dapat ditambahkan cakupannya.

Kelemahan ketiga berkaitan dengan bias seleksi. Fakta bahwa fasilitas kesehatan ini merupakan fasilitas kesehatan tersier dan rujukan Jawa Barat mengindikasikan bahwa terdapat selection bias pada pasien-pasien kami, di mana besar kemungkinan pasienpasien yang datang ke fasilitas kesehatan kami memiliki berbagai faktor risiko tambahan dan/atau keadaan klinis yang berbeda dengan profil demografis pasien-pasien umumnya. Akan lebih baik jika dibuat sebuah penelitian multisenter untuk mengurangi keberadaan bias ini.

Kesimpulan pada penelitian ini adalah pola kardiotokografi patologis secara signifikan meningkatkan risiko munculnya asfiksia pada neonatus.

\section{Daftar Pustaka}

1. Royal college of obstetrician and gynaeologists. RCOG e-learning accessed by registering on http;//www.elfh.org.uk/home

2. Gebrehiwot Teklehaimanot Gebregziabher, Fikaden Berhe Hadgu, Haftom Temesgen Abebe, "Prevalence and Associated Factors of Perinatal Asphyxia in Neonates Admitted to Ayder Comprehensive Specialized Hospital, Northern Ethiopia: A CrossSectional Study", International Journal of Pediatrics, vol. 2020, Article ID 4367248, 8pages, 2020. https://doi. org/10.1155/2020/4367248

3. Odd D, Heep A, Luyt K, Draycott T. Hypoxic-ischemic brain injury: Planned delivery before intrapartum events. Journal of Neonatal-Perinatal Medicine. 2017; 10:347-53.

4. Moshiro R, Mdoe P, Perlman JM. A Global View of Neonatal Asphyxia and Resuscitation. Frontiers in pediatrics. 2019; 7:489.

5. Devane D, Lalor JG, Daly S, McGuire W, Cuthbert A, Smith V. Cardiotocography versus intermittent auscultation of fetal heart on admission to labour ward for assessment of fetal wellbeing. The Cochrane database of systematic reviews. 2017;1:Cd005122. 
6. Cunningham F. Intrapartum Assessment in William Obstetrics. 23rd ed: Mc Graw Hills Companies; 2010.

7. Dhakare T, Patole K. A Study of Cardiotocography During Active Labour to Assess the Perinatal Outcome in High Risk Pregnancy. MVP Journal of Medical Sciences. 2016:92-5.

8. AAP Committee on Fetus and Newborn \& ACOG Committee on Obstetric Practice. The Apgar Score, American Academy of paediatrics, Pediatrics. 2015;136(4):819822

9. Murphy, K.W., Johnson, P., Moorcraft, J., Pattinson, R., Russell, V. and Turnbull, A. (1990), Birth asphyxia and the intrapartum cardiotocograph. BJOG: An International Journal of Obstetrics \& Gynaecology, 97: 470-479. doi:10.1111/j.1471-0528.1990. tb02515.x

10. Bogdanovic G, Babovic A, Rizvanovic M, Ljuca D, Grgic G, DjuranovicMilicic J. Cardiotocography in the prognosis of perinatal outcome. Med Arch . 2014;68(2):102-105. doi:10.5455/ medarh.2014.68.102-105

11. Dr. Hrishikesh Joshi, Dr. Suruchi M Pawar dan Dr. Akanksha Singh. Role of admission test by Cardiotocography (CTG) as a predictor of perinatal outcome: A prospective study. Int $\mathrm{J}$ Clin Obstet Gynae. 2019; 3(2): 128-131. DOI: 10.33545/gynae.2019.v3.i2c.21 